\title{
Article \\ A Polyphenol Enriched Variety of Apple Alters Circulating Immune Cell Gene Expression and Faecal Microbiota Composition in Healthy Adults: A Randomized Controlled Trial
}

Matthew P. G. Barnett ${ }^{1,2},{ }^{\mathbb{D}}$, Wayne Young ${ }^{1,2,3}$, Kelly Armstrong ${ }^{1}$, Diane Brewster ${ }^{4}$, Janine M. Cooney ${ }^{5}(\mathbb{D}$, Stephanie Ellett ${ }^{6}$, Richard V. Espley ${ }^{4}{ }^{\mathbb{D}}$, William Laing ${ }^{7}$, Paul Maclean ${ }^{1}$, Tony McGhie ${ }^{7}$, Greg Pringle ${ }^{4}$, Nicole C. Roy ${ }^{1,2,3,8,9}$ and Lynnette R. Ferguson ${ }^{6, *(1)}$

check for updates

Citation: Barnett, M.P.G.; Young, W.; Armstrong, K.; Brewster, D.; Cooney, J.M.; Ellett, S.; Espley, R.V.; Laing, W.; Maclean, P.; McGhie, T.; et al. A Polyphenol Enriched Variety of Apple Alters Circulating Immune Cell Gene Expression and Faecal Microbiota Composition in Healthy Adults: A Randomized Controlled Trial. Nutrients 2021, 13, 1092. https://doi.org/10.3390/ nu13041092

Academic Editor: Julio Galvez

Received: 8 March 2021

Accepted: 24 March 2021

Published: 27 March 2021

Publisher's Note: MDPI stays neutral with regard to jurisdictional claims in published maps and institutional affiliations.

Copyright: (c) 2021 by the authors. Licensee MDPI, Basel, Switzerland. This article is an open access article distributed under the terms and conditions of the Creative Commons Attribution (CC BY) license (https:// creativecommons.org/licenses/by/ $4.0 /)$.
1 AgResearch Limited, Grasslands Research Centre, Palmerston North 4442, New Zealand; wayne.young@agresearch.co.nz (W.Y.); kelly.armstrong@esr.cri.nz (K.A.); paul.maclean@agresearch.co.nz (P.M.); nicole.roy@otago.ac.nz (N.C.R.)

2 Riddet Institute, Palmerston North 4442, New Zealand

3 The High-Value Nutrition National Science Challenge, Auckland 1023, New Zealand

4 The New Zealand Institute for Plant and Food Research, Auckland 1025, New Zealand; di.brewster@plantandfood.co.nz (D.B.); richard.espley@plantandfood.co.nz (R.V.E.); greg.pringle@plantandfood.co.nz (G.P.)

5 The New Zealand Institute for Plant and Food Research, Hamilton 3214, New Zealand; janine.cooney@plantandfood.co.nz

6 Discipline of Nutrition and Dietetics, The University of Auckland, Private Bag 92019, Auckland 1142, New Zealand; steph@ellett.co.nz

7 The New Zealand Institute for Plant and Food Research, Palmerston North 4410, New Zealand; william.laing@plantandfood.co.nz (W.L.); tony.mcghie@plantandfood.co.nz (T.M.)

8 Liggins Institute, The University of Auckland, Auckland 1023, New Zealand

9 Department of Human Nutrition, University of Otago, Dunedin 9016, New Zealand

* Correspondence: matthew.barnett@agresearch.co.nz (M.P.G.B.); 1.ferguson@auckland.ac.nz (L.R.F.); Tel.: +64-9-923-1138 (L.R.F.)

\begin{abstract}
Polyphenols within fruits and vegetables may contribute to health benefits due to their consumption, with the anthocyanin sub-set also adding colour. The Lemonade ${ }^{\mathrm{TM}}$ apple variety has green skin and white flesh, with low anthocyanin content, while some apple varieties have high anthocyanin content in both the skin and flesh. Effects of red compared with white-fleshed apples were studied in healthy human subjects in a randomized, placebo-controlled, cross-over intervention trial. Twenty-five healthy subjects consumed dried daily portions of the red-fleshed or placebo (white-fleshed) apple for two weeks, followed by one-week washout and further two-week crossover period. During the study, volunteers provided faecal samples for microbiota composition analysis and blood samples for peripheral blood mononuclear cell (PBMC) gene expression analysis. Subtle differences were observed in the faecal microbiota of subjects that were fed the different apples, with significant $(p<0.05)$ reductions in relative abundances of Streptococcus, Ruminococcus, Blautia, and Roseburia, and increased relative abundances of Sutterella, Butyricicoccus, and Lactobacillus in subjects after consuming the red apple. Changes in PBMC gene expression showed 18 mRNA transcripts were differentially expressed between the two groups, of which 16 were immunoglobulin related genes. Pathway analysis showed that these genes had roles in pathways such as immunoglobulin production, B cell-mediated immunity, complement activation, and phagocytosis. In conclusion, this study shows that anthocyanin-rich apples may influence immune function compared to control apples, with changes potentially associated with differences in the faecal microbiota.
\end{abstract}

Keywords: Malus $\times$ domestica; RNA-Seq; 16s rRNA; immunoglobulins 


\section{Introduction}

The phrase "an apple a day keeps the doctor away" is thought to have originated in Wales, with a variant of it appearing in print in 1866 [1]. While it is a saying often used in jest, there is some recent evidence to support the notion of limited benefit to regular apple eaters for avoiding the use of health care services [2]. Certainly, apples are one of the fruits regularly incorporated into a Mediterranean-style diet [3-5]. Such a diet contains minimally processed fruits and vegetables, and is thought to be associated with a reduced risk of various chronic diseases, including cardiovascular disease, type 2 diabetes, and cancer. It may also lead to a slowing of disease progression [6]. The various phytochemicals contained within fruits and vegetables, including phenolics, flavonoids, triterpenoids and carotenoids, may play a key role in this reduction of chronic disease risk $[7,8]$.

The carbohydrate composition of dietary plant cell walls plays a significant role in the development and metabolism of the complex gut microbiota. Pectin is an essential component of plant cell walls. Chung et al. [9] confirmed that potentially beneficial Faecalibacterium prausnitzii strains could utilize apple pectin as a growth source. They also found that a different bacterium, the Firmicutes species Eubacterium eligens DSM3376, promotes the production of an anti-inflammatory cytokine, at least in cell-based assays. Other authors have shown potentially beneficial effects of the consumption of whole apples as opposed to a clear apple juice on circulating lipoproteins and blood pressure in a group of 23 healthy volunteers [10]. These endpoints are generally considered as biomarkers of cardiovascular disease risk. Thus, the authors concluded that, while the consumption of whole apples appears to show health benefits, drinking clear apple juice will not have the same effects, supporting the potential health benefits of consuming a whole fruit, possibly due to the fibre content [11].

The colour of an apple is also associated with health benefits. Polyphenols are a large and diverse class of compounds, and flavonoids, including the pigmented anthocyanins, are the largest and best-studied group of these $[12,13]$. These pigments are responsible for the red colouring of both the skin and/or flesh of an apple, and may confer health benefits. Indeed, Tu et al. attributed most of the reduced cancer risks seen in various studies to the flavonoid composition of the apple [13]. Andre et al. considered anti-inflammatory properties of extracts from five apple cultivars, selected mainly for variation in polyphenol composition [14]. They compared their effects in two cell-based assays, targeting critical points in the inflammation pathway, namely nuclear factor kappa B (NF- $\mathrm{KB}$ ) activation and expression of tumour necrosis factor alpha (TNF $\alpha)$, both implicated in the onset and progression of diseases associated with acute or chronic inflammation such as inflammatory bowel disease (IBD) [15] and neurodegenerative diseases [16]. They found that those with high levels of particular types of polyphenols targeted these two different, but important, parts of the inflammatory pathway in different ways.

Espley and coworkers showed that feeding mice a red-fleshed (flavonoid enriched) genetically modified variant of 'Royal Gala' apples not only reduced inflammatory biomarkers, but also beneficially modulated the colonic microbiota [17]. Polyphenols have poor bioavailability, mostly influenced by their complex chemical structures, which raises a question of their direct impact on health [18]. However, the primary mode through which these complex polyphenols are metabolized to smaller phenolic compounds is through the action of gut microorganisms [18]. Therefore, understanding the relationship between polyphenols and the microbes that metabolize them is essential for understanding their potential health benefits.

The effects of the red-fleshed apple in modulating the colonic microbiota in mice [17] is especially noteworthy. There is increasing evidence that the gut microbiome plays a critical role in susceptibility to various diseases that are important in humans [19]. At early life stages, it can impact on human growth and development, and there is also evidence that it may influence susceptibility to obesity at a later age [20-22]. In later life, the gut microbiome can also play a significant role in the development and progression of inflammatory bowel diseases, and indeed faecal transplants have been suggested as 
a possible therapy for some forms of these diseases [23]. The gut microbiome may be involved in cirrhosis of the liver due to non-alcoholic fatty liver disease [24], and may also play significant roles in both cancer development and response to specific therapies [25]; indeed, it significantly impacts the efficacy of several therapeutics [26].

Having demonstrated the beneficial effects of a red-fleshed apple in mouse studies, it now becomes essential to consider their effects in humans. Since genetically modified foods cannot ethically or legally be used in human studies in New Zealand, an initial step in this process was to select a naturally occurring type I red-fleshed apple [27]. The use of systems biology approaches to understand the effects of these apples in non-diseased subjects could enable a meaningful understanding of their potential for either helping to prevent disease or slow its progression $[28,29]$. In the current study, we investigated the hypothesis that two weeks' daily consumption of a red-fleshed apple would result in changes to the composition of the gut microbiota (assessed using microbial DNA extracted from faecal samples), and reduced expression of pro-inflammatory genes in peripheral blood mononuclear cells (PBMCs), compared with a white-fleshed control apple, in healthy adults.

\section{Materials and Methods}

\subsection{Preparation of Apples}

The high anthocyanin red-fleshed and placebo apples for this study were harvested in New Zealand in March 2014. The red-fleshed apples (Figure 1A; Malus $\times$ domestica, Plant \& Food Research selections A194R31T068, A236R02T092, and A358R02T100) were harvested from three trees. Placebo apples (Figure 1B) were M. domestica 'Lemonade ${ }^{\mathrm{TM}^{\prime}}$ (cultivar 'PremA153'), which were chosen due to their combination of pale skin and white flesh, and because they were available to harvest at the same time as the red-fleshed apples. All fruit came from the Hawkes Bay Research Centre, Plant \& Food Research. After removing the core, the apples were sliced and dipped in a food grade $2 \%$ calcium ascorbate solution, then freeze-dried. At this stage, all apples of each variety were mixed prior to packaging to ensure consistency of supply for the study. The dried apple slices were packaged under vacuum into daily portion sizes, each equivalent to one apple. All processing took place at the Food Bowl (Manukau, New Zealand) and was according to New Zealand Food Standards.
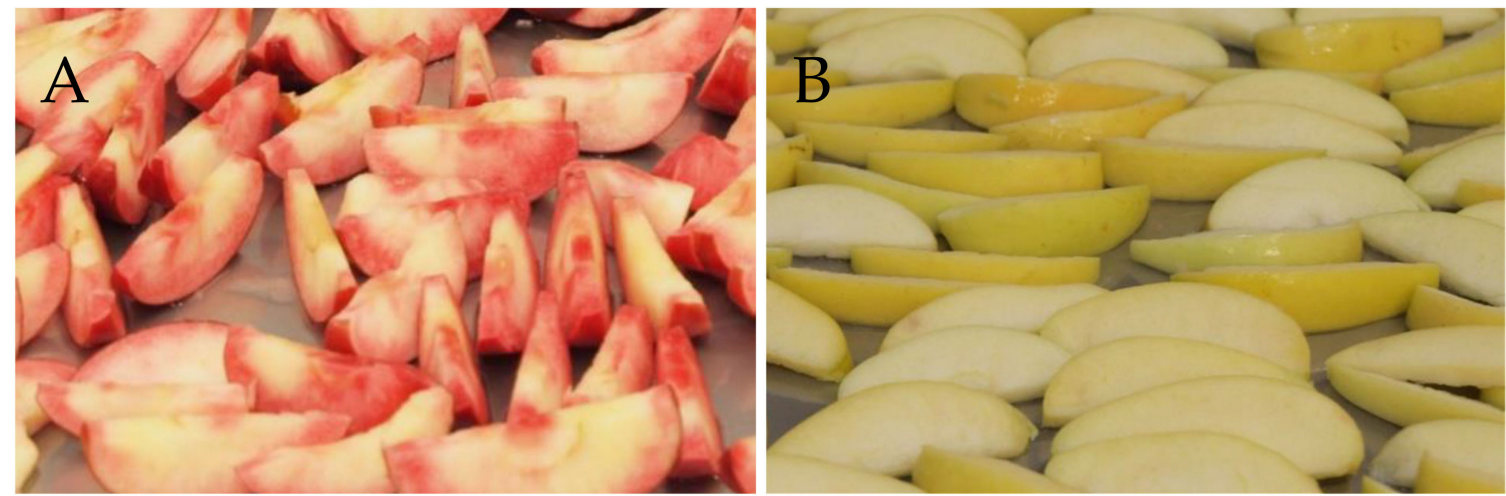

Figure 1. Red-fleshed (A) and white-fleshed placebo (B) apples after being sliced and dipped in food grade $2 \%$ calcium ascorbate.

\subsection{Analysis of Apple Polyphenols}

Liquid chromatography-mass spectrometry (LC-MS) grade acetonitrile, ethanol, methanol and formic acid were purchased from Thermo Fisher Scientific (Waltham, MA, USA) and ultrapure water was obtained from a Milli-Q Intergral3 system (Millipore, Merck KGaA, Darmstadt, Germany).

Freeze-dried apple fruit were provided for analysis. Each sample was the equivalent of a single apple and four samples were analysed per treatment. The sample (approximately $28 \mathrm{~g}$ dry weight) was extracted with $500 \mathrm{~mL}$ ethanol/water/formic acid (80:20:1 v/v/v) with incubation for $48 \mathrm{~h}$ at $2{ }^{\circ} \mathrm{C}$. Following centrifugation and $4 \times$ dilution with methanol, the 
sample extracts were transferred to LC vials and the polyphenol concentrations measured by LC with high-resolution, accurate-MS (LC-HRAM-MS).

The LC-HRAM-MS system was composed of a Dionex Ultimate ${ }^{\circledR} 3000$ Rapid Separation LC and a micrOTOF-Q II high-resolution mass spectrometer (Bruker Daltonics, Bremen, Germany) fitted with an electrospray ion source. The LC column was an YMC Triart C18 $150 \mathrm{~mm} \times 2.0 \mathrm{~mm}, 1.9 \mu \mathrm{m}$ (Kyoto, Japan) and was maintained at $40{ }^{\circ} \mathrm{C}$. The flow was $350 \mu \mathrm{L} \mathrm{min}{ }^{-1}$. The solvents were $A=1 \%$ formic acid and $B=100 \%$ acetonitrile. The solvent gradient was: Initial composition 90\% A 10\% B, 0-0.5 min; linear gradient to $65 \%$ A $35 \%$ B, 0.5-15 min; linear gradient to $50 \%$ A 50\% B, 15-18 min; linear gradient to $100 \% \mathrm{~B}, 18-22 \mathrm{~min}$; composition held at $100 \% \mathrm{~A}, 22-27 \mathrm{~min}$; linear gradient to $90 \% \mathrm{~A}$, $10 \% \mathrm{~B}, 22-22.2 \mathrm{~min}$; to return to the initial conditions before another sample injection at $32 \mathrm{~min}$. The injection volume for samples and standards was $1 \mu \mathrm{L}$. The micrOTOF-Q II parameters were: temperature $225^{\circ} \mathrm{C}$; drying $\mathrm{N}_{2}$ flow $6 \mathrm{~L} \mathrm{~min}^{-1}$; nebulizer $\mathrm{N}_{2} 1.5$ bar, endplate offset $500 \mathrm{~V}$, mass range 100-1500 Da, data were acquired at five scans s ${ }^{-1}$. Positive ion electrospray was used with a capillary voltage of $4000 \mathrm{~V}$. Post-acquisition internal mass calibration used sodium formate clusters with the sodium formate delivered by a syringe pump at the start of each chromatographic analysis. Data were processed using QuantAnalysis (Bruker Daltonics, Bremen, Germany).

Polyphenol concentrations were calculated by comparison to external calibration curves of authentic compounds (Sigma-Aldrich, St. Louis, MO, USA). When an authentic compound was not available, the calibration curve of a similar compound was used to calculate equivalents. Polyphenol content was calculated as mg per $100 \mathrm{~g}$ of freezedried apple.

\subsection{Clinical Trial Design}

The primary hypothesis was that two weeks' consumption of a red-fleshed apple, compared with a white-fleshed control apple, would result in significant changes in the composition of the faecal microbiota in healthy adults. Sample size was determined based on published studies in which dietary sources rich in polyphenols were assessed for impacts on relative levels of gut microbes. A difference of approximately 1\% (SD 1\%) was seen in the levels of Bifidobacteria when comparing the consumption of a wild blueberry drink to a placebo drink [30]. Similarly, in a study investigating red wine polyphenols, differences in Faecalibacterium prausnitzii and Roseburia of approximately $1.3(\log 10$ copies per gram of feces) were observed in healthy participants, with (SD approximately 1.2) [31]. Using these numbers as a basis, 20 healthy participants would give $90 \%$ power of detecting a difference with $p<0.05$. As the current study was comparing two different apple varieties, the observed differences were expected to be smaller than these reported values. We therefore recruited 30 participants, which allowed for 5 participants to drop out while still expecting to detect significant differences.

This study was a randomized, placebo-controlled, cross-over intervention trial. Thirty healthy volunteers of normal weight ( 25 female, 5 male; age 20-61 years; body mass index (BMI) $19.4-30.8 \mathrm{~kg} / \mathrm{m}^{2}$ ) were recruited by noticeboard advertisements at the University of Auckland and through advertising in local newspapers. Written informed consent was obtained from all subjects. This study was conducted according to the guidelines laid down in the Declaration of Helsinki and all procedures involving human subjects were approved by the New Zealand Health and Disability Ethics Committees (Reference number: NTY11/11/109/AM08). Exclusion criteria were a history of treatment for cancer in the previous five years (excluding non-melanoma skin cancers); a history of gastrointestinal disorders (ulcerative colitis, Crohn's Disease or Irritable Bowel Syndrome), a history of diabetes, cardiovascular disease, or liver or renal disorders. Other exclusion criteria were: any change in prescribed medication in the previous three months; antibiotics taken in the month prior to the study commencing; current smoker, or have previously smoked more than 10 pack years; consumption of more than four alcoholic beverages a day, or current use of vitamin or mineral supplements. 
Once selected for the study, a Food Variety Questionnaire was completed for two weeks prior to the commencement of the study. Participants were then randomly assigned to either consume the red-fleshed or white-fleshed apple, and were provided with sufficient for the first intervention. One portion (equivalent to one apple) of the dried slices of the assigned apple variety was consumed each day for the following two weeks. On their third visit (after washout) participants were provided with sufficient of the second apple variety for the cross-over intervention.

Participants were asked to refrain from eating any apples apart from those provided, but to otherwise maintain their regular diet and exercise levels throughout the study. Participants were also asked to complete a weekly questionnaire on the consumption of the following polyphenol-rich foods: fresh apple, red grapes/red grape juice, cranberries/cranberry juice, berries (including blueberries, raspberries, and blackberries), tea (green or black), red wine, red cabbage, eggplant (with skin on), red-fleshed peaches, red-fleshed plums, or black rice.

For each study visit, following an overnight fast, subjects either attended the Faculty of Medical and Health Sciences, The University of Auckland, or Plant \& Food Research, Mt Albert. Visits were on four separate occasions: before the intervention (baseline, week 0); at the end of the first intervention (week 2); after washout and before the second intervention (week 3); and at the end of the second intervention (end of trial, week 5). At each visit, height, weight and waist measurements were taken, and blood and urine samples collected. Participants also provided a faecal sample that had been collected during the $24 \mathrm{~h}$ prior to each visit.

\subsection{Blood Processing}

Venous blood samples were collected into ethylenediaminetetraacetic acid (EDTA)containing tubes (BD Vacutainer ${ }^{\circledR}$, Becton, Dickinson and Co., Franklin Lakes, NJ, USA), and centrifuged at $3000 \times g$ for $15 \mathrm{~min}$ at $4{ }^{\circ} \mathrm{C}$. Plasma was transferred into microtubes and stored at $-20^{\circ} \mathrm{C}$ until analysis. Cholesterol (total, high-density lipoprotein (HDL), total/HDL ratio, low-density lipoprotein (LDL) cholesterol), triglycerides, c-reactive protein (CRP) and a full blood count were measured (LabPLUS, Auckland, New Zealand).

\subsection{PBMC mRNA Sequencing and Analysis}

PBMCs were separated from whole blood by centrifugation in a Ficoll-Paque ${ }^{\mathrm{TM}}$ density gradient. Cell count and cell viability were assessed using an automated cell counter and trypan blue exclusion staining, respectively. RNA was extracted from PBMCs using an AllPrep DNA/RNA Kit (Qiagen, Germantown, MD, USA) as specified in the manufacturer's protocol. Following extraction, RNA quality was confirmed using a Bioanalyzer (Agilent Technologies, Palo Alto, CA, USA) and the RNA concentration measured using a nanodrop (NanoDrop Technologies, Wilmington, DE, USA). Only total RNA with a 260:280 nm ratio $\geq 2.0$, a 28S: 18 S peak ratio $\geq 0.8$ and an RNA integrity number $\geq 8.0$ was used for subsequent sequence analysis. PBMC gene expression was determined by RNAseq using Illumina HiSeq $2 \times 125$ PE sequencing.

Sequence reads were trimmed using flexbar version 2.4 [32] and mapped against the index prepared from the Human GRCh38 genome using RNA-star version 2.5.0c [33]. The non-directional counts of uniquely mapped read pairs were summed for each gene and analysed using the EdgeR package version 3.10.5 [34] in the R statistical software environment version 3.2.1. Quasi-likelihood negative binomial generalized linear models were generated from the counts within sample type. Pathway enrichment analysis was performed using the Clue Gene Ontology (ClueGO) package for Cytoscape.

\subsection{Analysis of Faecal Microbial Composition}

DNA from 98 faecal samples, from 25 volunteers (4 time-points [apple intervention start and end, with cross-over], two types of apples), were extracted using Nucleospin Soil kits (Macherey-Nagel, Düren, Germany). 
Barcode tagged Illumina 16S V3-V4 rRNA gene libraries were prepared and sequenced using the Illumina MiSeq 2X 250 bp PE platform at NZGL (Massey University, Palmerston North, New Zealand). Sequencing data was delivered as demultiplexed fastq files with adapter sequences trimmed. Sequences reads were processed and quality trimmed using QIIME $2[35,36]$ with a 25 q-score cut off and paired reads joined using vsearch with a minimum overlap of $20 \mathrm{bp}$ and no mismatched allowed. Remaining reads were denoised and chimera checked using the deblur algorithm. Sequence reads were classified by aligning against the Silva 132 small subunit ribosomal RNA database. Alpha diversity was assessed using the Faith's Phylogenetic Diversity metric and beta diversity was compared using Principal Coordinate Analysis (PCoA) of weighted unifrac phylogenetic distances. The sampling depth used for alpha and beta diversity analysis was 8000 reads. The total number of paired-end sequences that passed quality filtering was 2,462,081 (max 97,318; min 8028; median 23,469). Partial least squares discriminant analysis (PLS-DA) was performed on community compositions at intervention endpoints (T2 and T4) using the mixOmics package [37] for $R$.

\subsection{Statistical Analyses}

Differential gene expression in PBMCs was determined using Exact Tests for differences between two groups of Negative-Binomial Counts. Genes were considered differentially expressed with a 1.5-fold or more difference and a $p$-value equal to or less than 0.05 .

Differences in relative abundances of faecal microbes were analysed using a linear mixed-effects model with a nested design with patient factor nested with treatment sequence. Taxa with a $p$-value equal to or less than 0.05 were considered significantly different in relative abundance.

Other statistical analyses were performed with SPSS version 25 (SPSS, IBM Corporation, Armonk, NY, USA). Continuous data are presented as mean \pm standard deviation (SD).

\subsection{Sequence Data Access}

Sequences reads are available for download from the NCBI Sequence Read Archive, accession number PRJNA716437.

\section{Results}

\subsection{Apple Polyphenol Content}

LC-HRAM-MS analysis showed clear differences in the polyphenol content of the two apple varieties, with catechin, epicatechin, and the procyanidins B1, B2 and B5 being higher in the white-fleshed placebo apple, while cyanidin-3-glucoside, 4-p-coumaryl quinic acid, phloridzin, phloridzin xyloside, quercetin 3-arabinoside and quercetin 3-galactoside were all higher in the red-fleshed apple (all $p<0.001$; Table 1 ). 
Table 1. Polyphenol content of the two apple varieties, calculated as $\mathrm{mg} / 100 \mathrm{~g}$ freeze-dried apple. Data are expressed as mean \pm standard deviation.

\begin{tabular}{cccc}
\hline Compound & Red-Fleshed & Placebo & $p$-Value \\
\hline Chlorogenic acid & $116.7 \pm 13.5$ & $136.9 \pm 9.3$ & 0.102 \\
Catechin & $0.3 \pm 0.0$ & $9.9 \pm 1.7$ & $<0.001$ \\
Cyanidin 3-galactoside & $26.3 \pm 3.0$ & $0.0 \pm 0.0$ & $<0.001$ \\
Cyanidin 3-glucoside & $0.3 \pm 0.0$ & $0.0 \pm 0.0$ & $<0.001$ \\
Epicatechin & $3.0 \pm 0.4$ & $34.7 \pm 3.6$ & $<0.001$ \\
4-p-Coumaryl quinic acid & $0.0 \pm 0.0$ & $0.0 \pm 0.0$ & $\mathrm{~N} / \mathrm{A}$ \\
Phloridzin & $11.1 \pm 1.1$ & $6.0 \pm 1.2$ & $<0.01$ \\
Phloridzin xyloside & $119.4 \pm 10.7$ & $35.2 \pm 4.1$ & $<0.001$ \\
Procyanidin B1 & $0.2 \pm 0.0$ & $13.2 \pm 2.1$ & $<0.001$ \\
Procyanidin B2 & $4.3 \pm 0.1$ & $70.0 \pm 10.2$ & $<0.001$ \\
Procyanidin B5 & $0.5 \pm 0.1$ & $6.6 \pm 0.9$ & $<0.001$ \\
Quercetin 3-arabinoside & $2.1 \pm 0.1$ & $1.2 \pm 0.3$ & $<0.01$ \\
Quercetin 3-galactoside & $19.1 \pm 0.6$ & $6.5 \pm 2.7$ & $<0.001$ \\
Quercetin 3-rutinoside & $0.9 \pm 0.6$ & $0.6 \pm 0.3$ & 0.5339 \\
\hline
\end{tabular}

\subsection{Participant Characteristics}

A total of 25 participants completed the study; $n=20$ female, $n=5$ male (Figure 2 and Table 2). Baseline characteristics including anthropological measures, and fasting plasma lipids and CRP, are shown in Table 2. There were no significant differences in any of these parameters between participants based on sequence (i.e., between those receiving the red-fleshed apple first compared to those receiving the white-fleshed apple first (Table 2)), nor were there any differences in response to the apple treatment (i.e., an effect of the red-fleshed apple compared to the placebo, Table 3), or after the intervention period as a whole (Table 4). 


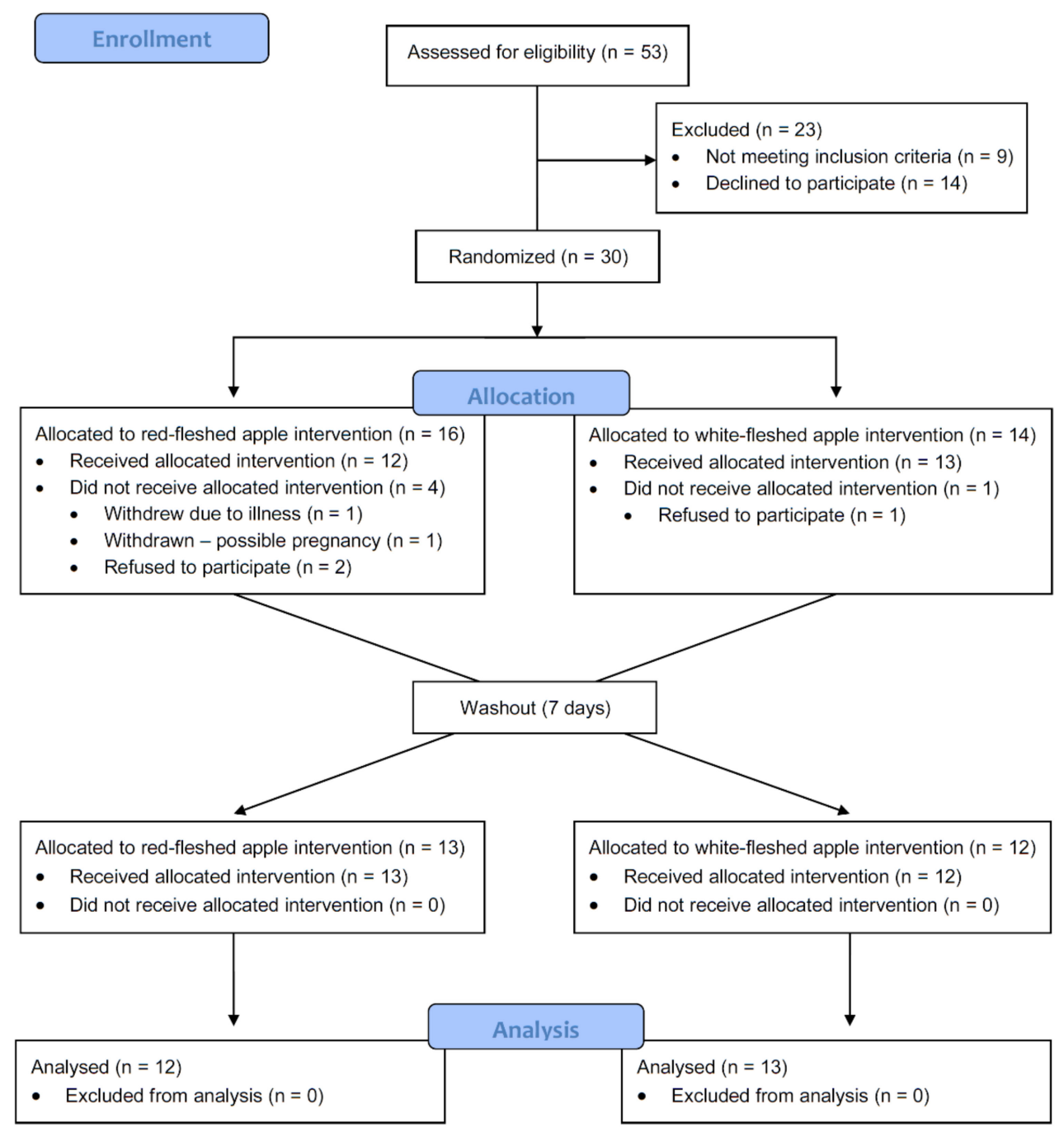

Figure 2. Consort flow diagram of study participant recruitment, intervention, and analysis; $\mathrm{n}$ refers to the number of participants at each stage.

Table 2. Baseline participant characteristics.

\begin{tabular}{|c|c|c|c|c|}
\hline \multirow{2}{*}{$\begin{array}{c}\text { Measure } \\
\text { Sequence }^{1}\end{array}$} & \multicolumn{2}{|c|}{ Female $(n=20)$} & \multicolumn{2}{|c|}{ Male $(n=5)$} \\
\hline & $1(n=10)$ & $2(n=10)$ & $1(n=2)$ & $2(n=3)$ \\
\hline $\mathrm{BMI}(\mathrm{kg} / \mathrm{m})^{2}$ & $23.3 \pm 3.0$ & $23.4 \pm 2.1$ & $22.8^{2}$ & $27.4 \pm 4.7$ \\
\hline Age (years) & $39.8 \pm 15.4$ & $38.0 \pm 13.0$ & $47.3 \pm 8.1$ & $39.7 \pm 14.2$ \\
\hline Cholesterol (mmol/L) & $4.87 \pm 1.18$ & $5.34 \pm 1.42$ & $6.25 \pm 2.62$ & $5.20 \pm 1.65$ \\
\hline HDL cholesterol (mmol/L) & $1.85 \pm 0.36$ & $1.76 \pm 0.20$ & $2.25 \pm 0.21$ & $1.40 \pm 0.46$ \\
\hline Chol/HDL ratio & $2.66 \pm 0.51$ & $3.06 \pm 0.94$ & $2.85 \pm 1.48$ & $4.03 \pm 1.68$ \\
\hline LDL cholesterol (mmol/L) & $2.65 \pm 0.99$ & $3.16 \pm 1.36$ & $3.40 \pm 2.40$ & $3.17 \pm 1.70$ \\
\hline Triglycerides (mmol/L) & $0.81 \pm 0.21$ & $0.94 \pm 0.39$ & $1.25 \pm 0.92$ & $1.40 \pm 0.72$ \\
\hline C-reactive protein $(\mathrm{CRP} ; \mathrm{mg} / \mathrm{L})^{3}$ & $5.70 \pm 12.01$ & $1.05 \pm 0.93$ & $1.00 \pm 0.00$ & $4.67 \pm 7.22$ \\
\hline
\end{tabular}

${ }^{1}$ Sequence refers to the order in which the two apples were consumed; 1 = red-fleshed apple first; 2 = placebo (white-fleshed) apple first. ${ }^{2}$ As a baseline BMI value was not obtained for one of the male participants, there is no standard deviation (SD) for this value. ${ }^{3}$ For CRP, several data values were below the lower limit of quantification (LLOQ); for analysis, these were set to $\frac{1}{2}$ LLOQ. Cholesterol, triglyceride and CRP measures are all in plasma. Abbreviations: $\mathrm{BMI}=$ body mass index; $\mathrm{HDL}=$ high-density lipoprotein; $\mathrm{LDL}=$ low-density lipoprotein; $n=$ number of participants. All data are presented as the mean $\pm \mathrm{SD}$. 
Table 3. Effect of red-fleshed apple on fasting plasma cholesterol, triglycerides, and CRP.

\begin{tabular}{cccc}
\hline Variable & Apple & Estimate (95\% CI) & $p$-Value \\
\hline CRP & Red & $-0.372(-0.976-0.232)$ & 0.2208 \\
& White & 0 & 0.2315 \\
\hline Cholesterol & Red & $-0.124(-0.329-0.082)$ & 0 \\
& White & $0.036(-0.114-0.186)$ & 0.6337 \\
\hline Cholesterol/HDL & Red & 0 & 0.0761 \\
& White & $-0.096(-0.203-0.011)$ & 0 \\
\hline HDL & Red & 0.5748 \\
\hline LDL & White & $-0.043(-0.198-0.111)$ & 0 \\
\hline
\end{tabular}

Abbreviations: $\mathrm{CI}$ = confidence interval; $\mathrm{CRP}=\mathrm{C}$-reactive protein; $\mathrm{HDL}$ = high-density lipoprotein; $\mathrm{LDL}=$ low-density lipoprotein. $\mathrm{All}$ data are presented as the mean \pm standard deviation.

Table 4. Effect of the overall intervention on fasting plasma cholesterol, triglycerides, and CRP.

\begin{tabular}{|c|c|c|c|c|c|}
\hline Variable & Intervention & $n$ & Mean \pm SD & Range & $p$-Value \\
\hline \multirow[t]{2}{*}{$\mathrm{CRP}\left(\mathrm{mg} \mathrm{L}^{-1}\right)$} & Before & 48 & $1.354 \pm 1.830$ & $0.5-9.0$ & 0.3648 \\
\hline & After & 49 & $1.286 \pm 1.373$ & $0.5-6.0$ & \\
\hline \multirow[t]{2}{*}{ Cholesterol } & Before & 50 & $5.128 \pm 1.359$ & $3.3-8.1$ & 0.0565 \\
\hline & After & 49 & $4.986 \pm 1.322$ & $3.1-8.0$ & \\
\hline \multirow[t]{2}{*}{ Cholesterol/HDL ratio } & Before & 50 & $2.956 \pm 0.945$ & $1.7-6.0$ & 0.8714 \\
\hline & After & 49 & $2.953 \pm 0.845$ & $1.7-5.6$ & \\
\hline \multirow[t]{2}{*}{ HDL } & Before & 50 & $1.794 \pm 0.363$ & $1.0-2.6$ & 0.1353 \\
\hline & After & 49 & $1.737 \pm 0.369$ & $1.0-2.6$ & \\
\hline \multirow{2}{*}{ LDL } & Before & 50 & $2.914 \pm 1.211$ & $1.2-5.7$ & 0.1293 \\
\hline & After & 49 & $2.831 \pm 1.144$ & $1.2-5.5$ & \\
\hline \multirow[t]{2}{*}{ Triglycerides } & Before & 50 & $0.918 \pm 0.411$ & $0.4-2.0$ & 0.9594 \\
\hline & After & 49 & $0.918 \pm 0.356$ & $0.3-2.1$ & \\
\hline
\end{tabular}

Abbreviations: $\mathrm{CRP}=\mathrm{C}$-reactive protein; $\mathrm{HDL}=$ high-density lipoprotein; $\mathrm{LDL}=$ low-density lipoprotein; $n=$ number of participants for which data are available. All data are presented as the mean \pm standard deviation (SD), with units $\mathrm{mmol} \mathrm{L}^{-1}$ unless otherwise defined; the range is also shown.

The data from the completed questionnaires regarding consumption of polyphenolrich foods do not suggest any difference in the frequency of consumption of these foods between the periods during which the different apples were consumed (i.e., there was no difference in overall consumption of these foods between treatments; data not shown), Therefore, it is unlikely these foods influenced the observed outcomes.

\subsection{PMBC Gene Expression}

Overall, few differences were detected in the PBMC transcriptome profiles of those receiving the different apple interventions; none reached the significance threshold after false discovery rate (FDR) correction. However, when using unadjusted p-values, 18 transcripts were differentially expressed. The use of unadjusted p-values should usually be treated with caution, but in this instance, all but 2 of these transcripts (nuclear receptor subfamily 4 group A member 3 (NR4A3), and resistin (RETN)) encoded immunoglobulin genes and of these, 14 were from the immunoglobulin variable regions (Table 5). This uniformity in the type of differentially expressed genes provide confidence that differences detected by the transcriptome analysis reflects a true biological difference that can be attributed to the difference apple interventions. Of the 18 genes identified as being differentially 
expressed (Table 5), only those that are annotated or have known links with each other were included in the network analysis. Therefore, 5 of the identified 18 genes are not shown in Figure 3. Pathway enrichment analysis using ClueGO showed that these genes had roles in pathways such as immunoglobulin production, B cell mediated immunity, complement activation, and phagocytosis (Figure 3).

Table 5. Differentially expressed genes between apple interventions.

\begin{tabular}{|c|c|c|c|c|c|}
\hline Ensembl ID & Gene Name & Description & $\operatorname{LogFC}$ & $\log C P M$ & $p$-Value \\
\hline ENSG00000243264 & IGKV2D-29 & Immunoglobulin kappa variable 2D-29 & 1.50 & 2.60 & $<0.001$ \\
\hline ENSG00000244575 & IGKV1-27 & Immunoglobulin kappa variable 1-27 & -1.38 & 4.00 & 0.002 \\
\hline ENSG00000211976 & IGHV3-73 & Immunoglobulin heavy variable 3-73 & 1.17 & 2.32 & 0.002 \\
\hline ENSG00000253998 & IGKV2-29 & Immunoglobulin kappa variable 2-29 & 1.05 & 0.59 & 0.002 \\
\hline ENSG00000224650 & IGHV3-74 & Immunoglobulin heavy variable 3-74 & 0.77 & 3.73 & 0.004 \\
\hline ENSG00000119508 & NR4A3 & Nuclear receptor subfamily 4 group A member 3 & -1.15 & 1.05 & 0.010 \\
\hline ENSG00000239571 & IGKV2D-30 & Immunoglobulin kappa variable 2D-30 & 0.79 & 0.81 & 0.013 \\
\hline ENSG00000211898 & IGHD & Immunoglobulin heavy constant delta & 0.77 & 7.06 & 0.014 \\
\hline ENSG00000104918 & RETN & Resistin & 0.71 & 2.85 & 0.015 \\
\hline ENSG00000239951 & IGKV3-20 & Immunoglobulin kappa variable 3-20 & -0.90 & 6.79 & 0.019 \\
\hline ENSG00000211970 & IGHV4-61 & Immunoglobulin heavy variable 4-61 & -1.12 & 3.16 & 0.025 \\
\hline ENSG00000211639 & IGLV4-60 & Immunoglobulin lambda variable 4-60 & -1.13 & 1.90 & 0.025 \\
\hline ENSG00000211945 & IGHV1-18 & Immunoglobulin heavy variable 1-18 & -0.81 & 3.23 & 0.033 \\
\hline ENSG00000211670 & IGLV3-9 & Immunoglobulin lambda variable 3-9 & 0.71 & 1.97 & 0.033 \\
\hline ENSG00000239855 & IGKV1-6 & Immunoglobulin kappa variable 1-6 & 0.64 & 2.66 & 0.046 \\
\hline ENSG00000211611 & IGKV6-21 & Immunoglobulin kappa variable 6-21 & 0.65 & 0.88 & 0.047 \\
\hline ENSG00000211668 & IGLV2-11 & Immunoglobulin lambda variable 2-11 & -0.77 & 4.25 & 0.047 \\
\hline ENSG00000211895 & IGHA1 & Immunoglobulin heavy constant alpha 1 & -0.89 & 9.78 & 0.048 \\
\hline
\end{tabular}

$\log F C=\log 2$ fold change, $\log C P M=\log 2$ counts per million. Positive LogFC value indicates higher expression in the placebo (whitefleshed) apple group; negative $\mathrm{Log} F \mathrm{C}$ indicates lower expression in the placebo apple group.

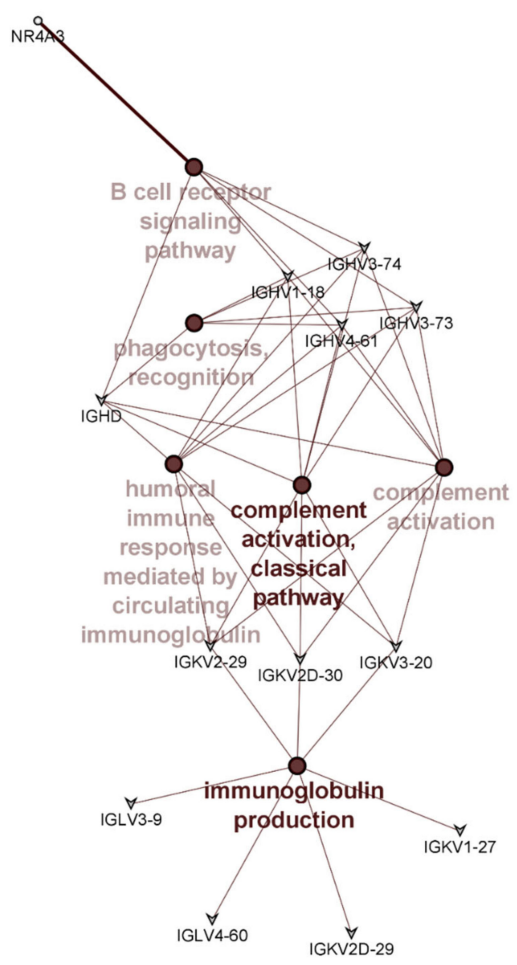

Figure 3. Pathway enrichment analysis showing pathways significantly enriched with differentially expressed genes between the different apple interventions. Colour intensities indicate significance of enrichment with darker colour indicating increasing significance. Genes common to different pathways are shown. 


\subsection{Faecal Microbiota Composition}

Overall, there were few differences in the faecal microbiota composition that could be attributed to the type of apple intervention (Figures 4 and 5). However, some differences in community composition could be discerned by partial least squares discriminant analysis (PLS-DA, Figure 6). Differences observed were subtle, with significant reductions $(p<0.05)$ in relative abundances of genera that included Streptococcus, Ruminococcus, Blautia, and Roseburia after consuming the red-fleshed apple (Table 6). In contrast, the relative abundance of other taxa, such as Sutterella, Butyricicoccus, and Lactobacillus was increased in subjects after consumption of the red-fleshed apple (Table 6).

Table 6. Taxa with significantly different mean relative abundances between apple interventions (linear mixed-effects model).

\begin{tabular}{ccccc}
\hline Phylum & Genus & Red & White & $p$-Value \\
\hline Firmicutes & Blautia & $2.53 \pm 0.32$ & $3.12 \pm 0.32$ & 0.049 \\
Firmicutes & Roseburia & $2.30 \pm 0.26$ & $3.07 \pm 0.35$ & 0.041 \\
Firmicutes & Phascolarctobacterium & $1.75 \pm 0.33$ & $2.79 \pm 0.59$ & 0.045 \\
Firmicutes & Ruminococcus 1 & $1.10 \pm 0.21$ & $1.69 \pm 0.28$ & 0.024 \\
Proteobacteria & Sutterella & $0.50 \pm 0.12$ & $0.33 \pm 0.07$ & 0.026 \\
Firmicutes & Lactobacillus & $0.30 \pm 0.19$ & $0.04 \pm 0.02$ & 0.045 \\
Bacteroidetes & Coprobacter & $0.27 \pm 0.18$ & $0.11 \pm 0.04$ & 0.001 \\
Firmicutes & Butyricicoccus & $0.23 \pm 0.04$ & $0.18 \pm 0.03$ & 0.049 \\
Firmicutes & Streptococcus & $0.18 \pm 0.05$ & $0.36 \pm 0.08$ & 0.015 \\
Firmicutes & Intestinibacter & $0.17 \pm 0.04$ & $0.25 \pm 0.05$ & 0.050 \\
Proteobacteria & Haemophilus & $0.12 \pm 0.12$ & $0.24 \pm 0.17$ & 0.037 \\
Tenericutes & uncl. Mollicutes RF39 & $0.11 \pm 0.03$ & $0.21 \pm 0.06$ & 0.033 \\
Firmicutes & Terrisporobacter & $0.09 \pm 0.03$ & $0.22 \pm 0.09$ & 0.042 \\
Tenericutes & unclassified Izimaplasmatales & $0.03 \pm 0.02$ & $0.09 \pm 0.06$ & 0.041 \\
Firmicutes & Uncl. Ruminococcaceae UCG 011 & $0.02 \pm 0.01$ & $0.01 \pm 0.00$ & 0.040 \\
\hline
\end{tabular}

Faecal samples showed communities typical of human intestinal microbiota (dominated by Firmicutes and Bacteriodetes) that was highly variable between individuals and samples. No significant differences in alpha diversity (Faith's phylogenetic diversity and Chao1 indices) were observed between interventions (data not shown).
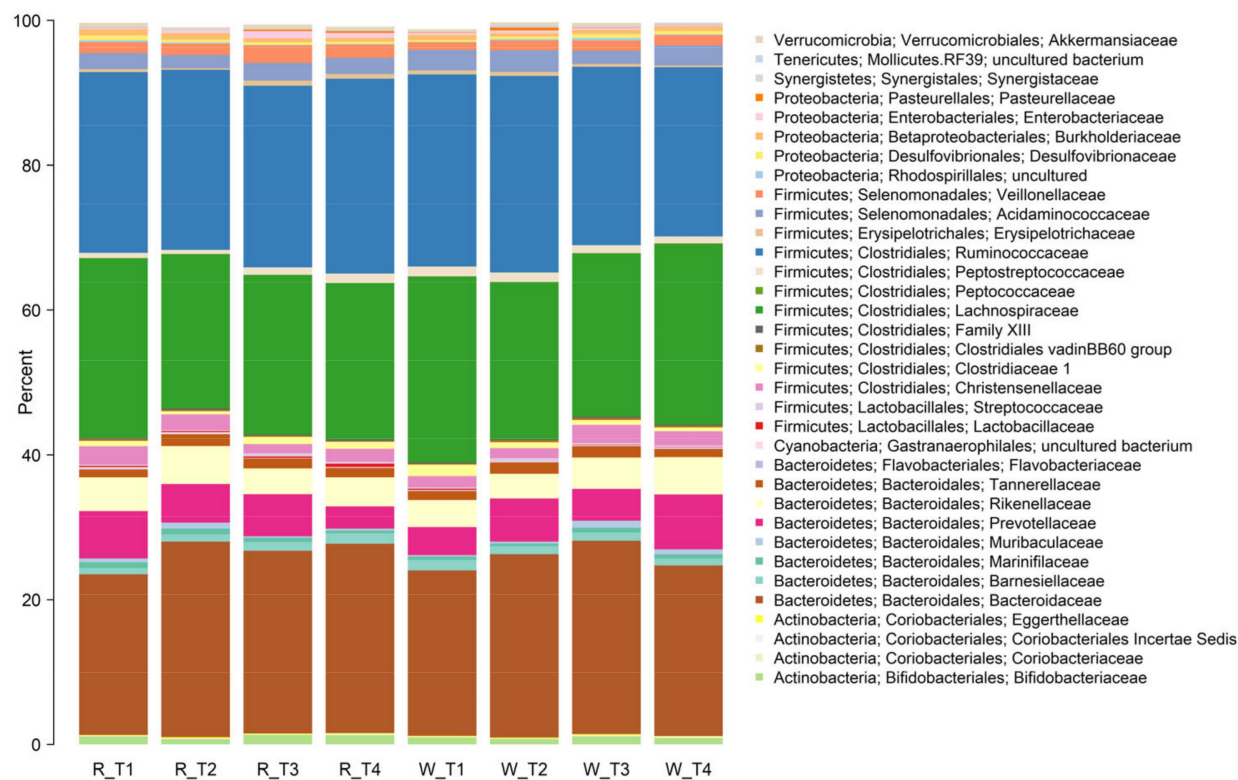

Figure 4. Stacked bar plot showing mean relative abundances of taxa at the family level for those consuming red-fleshed (R) apples and placebo or white-fleshed (W) apples at the start of each intervention period (T1 and T3) and at the end of each intervention period (T2 and T4). 

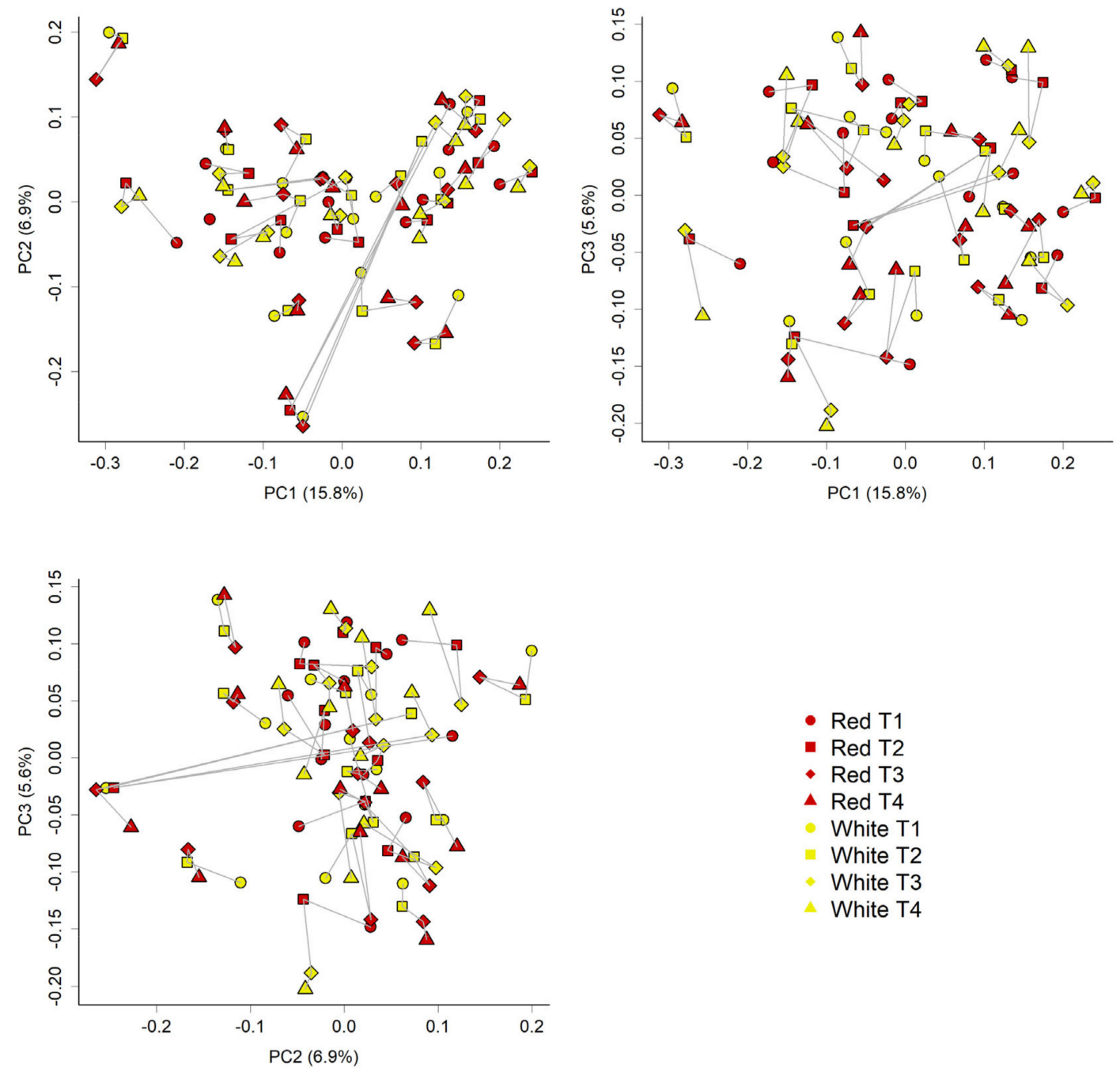

- Red T1

- Red T2

Red T3

Red T4

White T1

White T2

White T3

White T4

Figure 5. Unweighted unifrac phylogenetic distance analyses of communities reiterate the variability between samples. The Principle coordinate analysis (PCoA) plots below shows the community similarity between samples; Red = red-fleshed apple; yellow = placebo (white-fleshed) apple; spheres = T1 (baseline, week 0); squares = T2 (at the end of the first intervention, week 2); diamonds = T3 (after washout and before the second intervention, week 3); triangles = T4 (at the end of the second intervention which is also the end of trial, week 5). Different plots show PC1 vs. PC2, PC1 vs. PC3, and PC2 vs. PC3. Lines join samples from the same donor. Here, we can see that the donor has the most influence on composition, as would be expected. No obvious differences based on treatments were observed. 


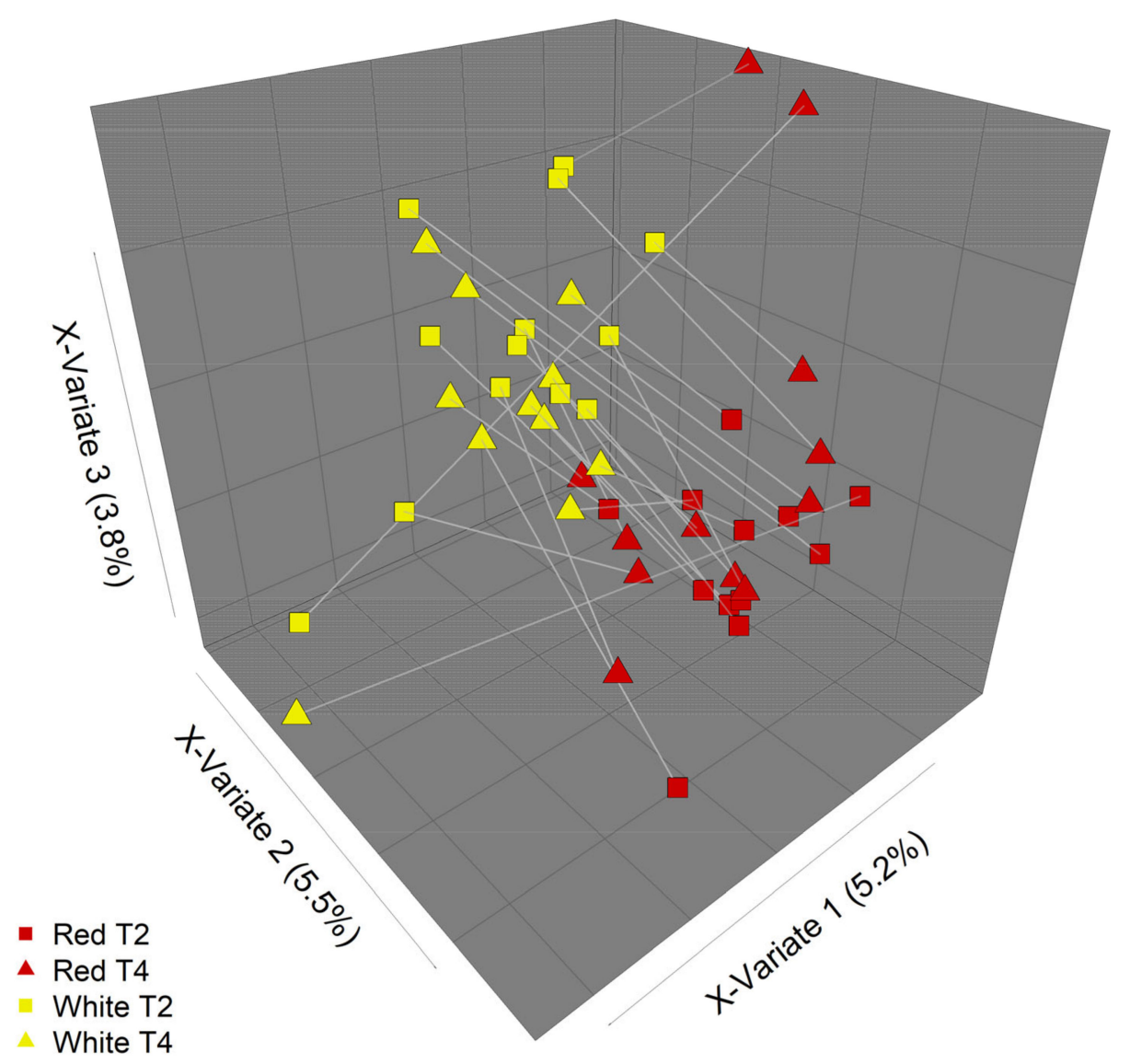

Figure 6. Partial least squares discriminant analysis (PLS-DA) of microbial community composition in response to different apple treatments. Some differences in community composition between the two apple interventions ("Red" = red-fleshed, "White" = white-fleshed) can be discerned by PLS-DA. Plot shows communities at intervention endpoints (T2 and T4). Lines join samples from the same participant.

\section{Discussion}

The gut microbiota is known to play an essential role in the transformation of many complex plant polyphenols [38]. There is evidence that the presence of specific microbial species or genera can influence the host's ability to metabolise particular polyphenols, with the bioactivity and bioavailability of many dietary flavonoids being influenced by gastrointestinal microbiome metabolism [39]. Conversely, although the influence of habitual flavonoid intake on the gut microbiome is poorly understood [39], a range of human, animal and in vitro studies have demonstrated that polyphenols from a range of different sources, including berries [30,40,41], tea [42], red wine [31,42,43] and cocoa [44] can modulate the relative levels of intestinal (generally colonic or faecal) microbes. These changes to the microbiota may include inhibiting potential pathogens and increasing levels of putative beneficial microbes [31].

The different apple interventions in the current study (a high anthocyanin red-fleshed apple and a white-fleshed placebo apple) had only minor effects on the composition of the faecal microbiota, a proxy of the composition of the microbiota in the lower intestine. However, the differences that were observed included genera typically associated with fibre degradation and short-chain fatty acid production, such as Roseburia and Ruminococcus [45]. These genera were decreased as a result of the red-fleshed apple intervention, which does suggest some potential differences in the fibre content and/or composition between the apple types. Blautia was another genus decreased by the red-fleshed apple intervention. Blautia, while not typically associated with fibre degradation in humans, has been shown to 
degrade some digestion resistant carbohydrates in vitro [46], and is responsive to dietary carbohydrate levels $[47,48]$. However, it has also been shown to be reduced in response to black tea and red wine grape extract in an in vitro gut microbial ecosystem [42], an effect the authors suggested was due to the polyphenol content. This is consistent with the idea that the change in Blautia observed in the current study is due to the difference in polyphenol content of the two apples. Streptococcus, which was decreased by the red-fleshed apple intervention, has also been shown to have an inverse association with dietary fructose levels [49], which may also point to a differential effect on the gut microbiome according to nutrient composition.

The red-fleshed apple intervention did increase Lactobacillus relative abundance. Although the precise mechanism for this increase cannot be established here, numerous studies have highlighted the potential for polyphenols to stimulate expansion or activity of Lactobacillus $[18,50,51]$, and our results are consistent with these studies. Lactic acid bacteria such as Lactobacillus and Bifidobacterium have a long association with health benefits, so the increased relative abundance of Lactobacillus after the red-fleshed apple intervention is a notable finding. Butyricicoccus, a butyrate producer, was another bacterium associated with health benefits [52-54] that was increased in response to consumption of the red-fleshed apple. However, there were other changes to the faecal microbial community after consumption of the red-fleshed apples that could be considered negative or detrimental; Roseburia, a prominent butyrate producer $[48,55,56]$ was decreased, and Sutterella, a Proteobacteria often associated with disease conditions $[57,58]$, was increased after the redfleshed apple intervention. These changes reiterate the complexity of the gut microbiome and that changes can rarely be classified as simply "good" or "bad".

Analysing PBMC gene expression profiles can be useful to identify biomarkers of physiological responses, and these profiles have been shown to respond to diet [59]. In our study, subtle shifts in PBMC gene expression were observed between the different apple interventions. Previous data showed changes in mice, but with a genetically modified organism (GMO) apple. This study has shown similar results, but with a non-GMO apple. These changes were predominantly related to genes encoding the immunoglobulin variable regions. Although these changes were not statistically significant after false discovery rate correction (and should therefore be interpreted with some caution), the common functional motif lends credence to these changes being based on an underlying biological mechanism rather than simply being a type 1 error (i.e., a false positive). Our results suggest that the consumption of polyphenol-rich red-fleshed apples for two weeks can alter immune responses through modulation of immunoglobulin expression. This premise is supported by a previous study in rodents where cocoa polyphenols increased serum immunoglobulin (Ig)G and faecal IgA levels [44]. However, the overall physiological relevance and impact of the observed PBMC gene expression changes remain to be determined.

It is possible that clearer differences may have been observed with a longer duration of intervention. A number of other studies which have investigated the impact of polyphenol consumption have been of a greater duration, however this has not necessarily meant the observation of clearer effects of the intervention. For example, an intervention investigating the impact of a polyphenol-rich tart cherry extract (4 weeks) did not show any impact on the gut microbiome [60]. Conversely, several studies are reported in which significant differences in metabolic and/or microbial responses have been seen with an intervention of two weeks' duration or less, for example pomegranate juice [61] or cranberries [41]. Thus, we believe that the duration of the current study was sufficient to identify any differences, even though these differences were relatively subtle.

It is possible that the predominance of women taking part in the study and the large age range (20-61years) and BMI $\left(19.4-30.8 \mathrm{~kg} / \mathrm{m}^{2}\right)$ of the participants may have affected the results of the study. The fact that differences were observed in spite of the age and BMI range mean that these results can be considered as valid to a wide proportion of the general healthy adult population. However, with only five male participants it is not possible to 
draw any conclusions regarding gender-specific effects, and any future studies would have a more balanced gender ratio to address this.

This study does have some limitations. First, because the two apples used were clearly visually different participants could not be blinded. It is therefore possible that there were effects on the faecal microbiota and/or PBMC gene expression as a result of the participants' expectations. However, studies in which polyphenols were administered in a blinded manner have shown an impact on the faecal microbiota [62] suggesting it is reasonable to conclude that the results observed here are as a result of the different apple per se.

With regard to the differences between apple varieties, it is possible that other compositional differences between apples (e.g., fibre) may have had some impact on the observed outcomes, reflected in differences in fibre-degrading species such as Roseburia. Although we do not have compositional analyses of the specific apples used in this study, it is known that apple composition varies quantitatively to some extent between different varieties (e.g., [63]). Polyphenols are a class of compound that shows particularly large differences, whereas factors such as fibre content are less variable [64]. Further, the two cultivars in our study varied qualitatively in their anthocyanins (red versus not red) and this is reflected in the large quantitative differences in polyphenol content, and changes in genera such as Blautia are consistent with a response to the polyphenols themselves. Thus, we maintain it is reasonable to conclude that at least some of the observed effects were due to the relatively large differences in polyphenol content.

In addition, the 16S rRNA analyses only provide data regarding microbiota community composition; there is no information relating to the underlying genetic makeup of the microbiome, which would be shown using techniques such as shotgun metagenomics. It is, therefore, possible that differences in the genetic potential of the microbiome occurred. Finally, although they were significant, changes in the composition of the faecal microbiota were relatively modest, and it is not clear whether such changes would have long-term implications for health. Another limitation relates to the use of PBMCs to investigate the effects of foods on the human immune system [65] due to the relative ease of collection. However, because PBMCs represent a heterogeneous mixture of different cell types, including T cells, B cells, natural killer (NK) T cells, and monocytes, impacts on the immune system may not always be clear cut. Circulating PBMCs will also be different from immune cells isolated from the gut or lymphatic tissues.

\section{Conclusions}

Results from this study show that naturally bred, anthocyanin-enriched red-fleshed apples may influence immune function compared to non-enriched apples, which have a different anthocyanin profile, and these changes are potentially associated with differences in the faecal microbiota. Therefore, consumption of these apples may have health benefits, in addition to those associated with the consumption of apples per se. However, the mechanistic links between compositional changes in the faecal microbiota and PBMC immunoglobulin gene expression in this study remain to be determined.

Author Contributions: Conceptualization, M.P.G.B., W.L., N.C.R. and L.R.F.; Formal analysis, M.P.G.B., W.Y., S.E. and P.M.; Funding acquisition, W.L., G.P., N.C.R. and L.R.F.; Investigation, W.Y., K.A., D.B., J.M.C., S.E., R.V.E., W.L., P.M., T.M., G.P. and L.R.F.; Methodology, D.B., J.M.C., R.V.E. and T.M.; Project administration, S.E.; Writing-original draft, M.P.G.B., W.Y. and L.R.F.; Writing-review and editing, K.A., D.B., J.M.C., S.E., R.V.E., W.L., P.M., T.M., G.P. and N.C.R. All authors have read and agreed to the published version of the manuscript.

Funding: This study was part of Nutrigenomics New Zealand, a collaboration between AgResearch Ltd., Plant \& Food Research Ltd. and The University of Auckland and was primarily funded by the New Zealand Ministry of Business, Innovation and Employment (MBIE, Contract Nos.: C02X0403, C11X1009). Additional funding was provided by Prevar (Contract No. 30897). 
Institutional Review Board Statement: This study was conducted according to the guidelines laid down in the Declaration of Helsinki and all procedures involving human subjects were approved by the New Zealand Health and Disability Ethics Committees (Reference number: NTY11/11/109/AM08, approved 2013).

Informed Consent Statement: Written informed consent was obtained from all subjects.

Data Availability Statement: Sequences reads for $16 S$ rRNA (faecal microbiota) and RNASeq (PBMC gene expression) are available for download from the NCBI Sequence Read Archive, accession number PRJNA716437.

Acknowledgments: The authors thank the human volunteers who diligently followed the trial design, and provided the necessary samples. We also acknowledge Rosemary Weskett and Natalie Proffit (Plant \& Food Research) for picking and packing the apples used in this study.

Conflicts of Interest: The authors declare no conflict of interest. The funders had no role in the design of the study; in the collection, analyses, or interpretation of data; in the writing of the manuscript, or in the decision to publish the results.

\section{References}

1. Phillips, J.P. A Pembrokeshire Proverb. Notes Queries 1866, 127, 153. [CrossRef]

2. Davis, M.A.; Bynum, J.P.; Sirovich, B.E. Association between Apple Consumption and Physician Visits: Appealing the Conventional Wisdom That an Apple a Day Keeps the Doctor Away. JAMA Intern. Med. 2015, 175, 777-783. [CrossRef]

3. Chatzi, L.; Apostolaki, G.; Bibakis, I.; Skypala, I.; Bibaki-Liakou, V.; Tzanakis, N.; Kogevinas, M.; Cullinan, P. Protective Effect of Fruits, Vegetables and the Mediterranean Diet on Asthma and Allergies among Children in Crete. Thorax 2007, 62, 677-683. [CrossRef] [PubMed]

4. Tosti, V.; Bertozzi, B.; Fontana, L. Health Benefits of the Mediterranean Diet: Metabolic and Molecular Mechanisms. J. Gerontol. A Biol. Sci. Med. Sci. 2018, 73, 318-326. [CrossRef]

5. Zamora-Ros, R.; Andres-Lacueva, C.; Lamuela-Raventós, R.M.; Berenguer, T.; Jakszyn, P.; Barricarte, A.; Ardanaz, E.; Amiano, P.; Dorronsoro, M.; Larrañaga, N.; et al. Estimation of Dietary Sources and Flavonoid Intake in a Spanish Adult Population (EPIC-Spain). J. Am. Diet. Assoc. 2010, 110, 390-398. [CrossRef] [PubMed]

6. Martín-Peláez, S.; Fito, M.; Castaner, O. Mediterranean Diet Effects on Type 2 Diabetes Prevention, Disease Progression, and Related Mechanisms. A Review. Nutrients 2020, 12, 2236. [CrossRef] [PubMed]

7. Boyer, J.; Liu, R.H. Apple Phytochemicals and Their Health Benefits. Nutr. J. 2004, 3, 5. [CrossRef] [PubMed]

8. Gerhauser, C. Cancer Chemopreventive Potential of Apples, Apple Juice, and Apple Components. Planta Med. 2008, 74, 1608-1624. [CrossRef] [PubMed]

9. Chung, W.S.F.; Meijerink, M.; Zeuner, B.; Holck, J.; Louis, P.; Meyer, A.S.; Wells, J.M.; Flint, H.J.; Duncan, S.H. Prebiotic Potential of Pectin and Pectic Oligosaccharides to Promote Anti-Inflammatory Commensal Bacteria in the Human Colon. FEMS Microbiol. Ecol. 2017, 93, fix127. [CrossRef] [PubMed]

10. Ravn-Haren, G.; Dragsted, L.O.; Buch-Andersen, T.; Jensen, E.N.; Jensen, R.I.; Németh-Balogh, M.; Paulovicsová, B.; Bergström, A.; Wilcks, A.; Licht, T.R.; et al. Intake of Whole Apples or Clear Apple Juice Has Contrasting Effects on Plasma Lipids in Healthy Volunteers. Eur. J. Nutr. 2013, 52, 1875-1889. [CrossRef] [PubMed]

11. Wong, C.; Harris, P.J.; Ferguson, L.R. Potential Benefits of Dietary Fibre Intervention in Inflammatory Bowel Disease. Int. J. Mol. Sci. 2016, 17, 919. [CrossRef] [PubMed]

12. Ferguson, L.R. Role of Plant Polyphenols in Genomic Stability. Mutat. Res. 2001, 475, 89-111. [CrossRef]

13. Tu, S.H.; Chen, L.C.; Ho, Y.S. An Apple a Day to Prevent Cancer Formation: Reducing Cancer Risk with Flavonoids. J. Food Drug Anal. 2017, 25, 119-124. [CrossRef] [PubMed]

14. Andre, C.M.; Greenwood, J.M.; Walker, E.G.; Rassam, M.; Sullivan, M.; Evers, D.; Perry, N.B.; Laing, W.A. Anti-Inflammatory Procyanidins and Triterpenes in 109 Apple Varieties. J. Agric. Food Chem. 2012, 60, 10546-10554. [CrossRef]

15. Ardite, E.; Panés, J.; Miranda, M.; Salas, A.; Elizalde, J.I.; Sans, M.; Arce, Y.; Bordas, J.M.; Fernández-Checa, J.C.; Piqué, J.M. Effects of Steroid Treatment on Activation of Nuclear Factor KappaB in Patients with Inflammatory Bowel Disease. Br. J. Pharmacol. 1998, 124, 431-433. [CrossRef]

16. Clark, I.A.; Vissel, B. Broader Insights into Understanding Tumor Necrosis Factor and Neurodegenerative Disease Pathogenesis Infer New Therapeutic Approaches. J. Alzheimers Dis. 2021, 79, 931-948. [CrossRef]

17. Espley, R.V.; Butts, C.A.; Laing, W.A.; Martell, S.; Smith, H.; McGhie, T.K.; Zhang, J.; Paturi, G.; Hedderley, D.; Bovy, A.; et al. Dietary Flavonoids from Modified Apple Reduce Inflammation Markers and Modulate Gut Microbiota in Mice. J. Nutr. 2014, 144, 146-154. [CrossRef] [PubMed]

18. Lavefve, L.; Howard, L.R.; Carbonero, F. Berry Polyphenols Metabolism and Impact on Human Gut Microbiota and Health. Food Funct. 2020, 11, 45-65. [CrossRef] [PubMed]

19. Knight, R. Expanding Our Understanding of the Role of the Microbiome in Health and Disease. Arch. Med. Res. 2017, 48, 663-665. [CrossRef] 
20. Dominguez-Bello, M.G.; Godoy-Vitorino, F.; Knight, R.; Blaser, M.J. Role of the Microbiome in Human Development. Gut 2019, 68, 1108-1114. [CrossRef]

21. Stanislawski, M.A.; Dabelea, D.; Wagner, B.D.; Iszatt, N.; Dahl, C.; Sontag, M.K.; Knight, R.; Lozupone, C.A.; Eggesbo, M. Gut Microbiota in the First 2 Years of Life and the Association with Body Mass Index at Age 12 in a Norwegian Birth Cohort. mBio 2018, 9, e01751-18. [CrossRef] [PubMed]

22. Tran, H.Q.; Mills, R.H.; Peters, N.V.; Holder, M.K.; de Vries, G.J.; Knight, R.; Chassaing, B.; Gonzalez, D.J.; Gewirtz, A.T. Associations of the Fecal Microbial Proteome Composition and Proneness to Diet-Induced Obesity. Mol. Cell. Proteom. 2019, 18, 1864-1879. [CrossRef] [PubMed]

23. Lloyd-Price, J.; Arze, C.; Ananthakrishnan, A.N.; Schirmer, M.; Avila-Pacheco, J.; Poon, T.W.; Andrews, E.; Ajami, N.J.; Bonham, K.S.; Brislawn, C.J.; et al. Multi-Omics of the Gut Microbial Ecosystem in Inflammatory Bowel Diseases. Nature 2019, 569, 655-662. [CrossRef] [PubMed]

24. Caussy, C.; Tripathi, A.; Humphrey, G.; Bassirian, S.; Singh, S.; Faulkner, C.; Bettencourt, R.; Rizo, E.; Richards, L.; Xu, Z.Z.; et al A Gut Microbiome Signature for Cirrhosis Due to Nonalcoholic Fatty Liver Disease. Nat. Commun. 2019, 10, 1406. [CrossRef]

25. Rajagopala, S.V.; Vashee, S.; Oldfield, L.M.; Suzuki, Y.; Venter, J.C.; Telenti, A.; Nelson, K.E. The Human Microbiome and Cancer. Cancer Prev. Res. (Phila.) 2017, 10, 226-234. [CrossRef] [PubMed]

26. Vázquez-Baeza, Y.; Callewaert, C.; Debelius, J.; Hyde, E.; Marotz, C.; Morton, J.T.; Swafford, A.; Vrbanac, A.; Dorrestein, P.C.; Knight, R. Impacts of the Human Gut Microbiome on Therapeutics. Annu. Rev. Pharmacol. Toxicol. 2018, 58, 253-270. [CrossRef]

27. Volz, R.K.; Oraguzie, N.C.; Whitworth, C.J.; How, N.; Chagné, D.; Carlisle, C.M.; Gardiner, S.E.; Rikkerink, E.H.A.; Lawrence, T. Breeding for Red Flesh Colour in Apple: Progress and Challenges. Acta Hortic. 2009, 814, 337-342. [CrossRef]

28. Ferguson, L.R.; Barnett, M.P. Why Are Omics Technologies Important to Understanding the Role of Nutrition in Inflammatory Bowel Diseases? Int. J. Mol. Sci. 2016, 17, 1763. [CrossRef] [PubMed]

29. van Ommen, B.; Stierum, R. Nutrigenomics: Exploiting Systems Biology in the Nutrition and Health Arena. Curr. Opin. Biotechnol. 2002, 13, 517-521. [CrossRef]

30. Gomes, A.; Oudot, C.; Macià, A.; Foito, A.; Carregosa, D.; Stewart, D.; Van de Wiele, T.; Berry, D.; Motilva, M.J.; Brenner, C.; et al. Berry-Enriched Diet in Salt-Sensitive Hypertensive Rats: Metabolic Fate of (Poly)Phenols and the Role of Gut Microbiota. Nutrients 2019, 11, 2634. [CrossRef]

31. Moreno-Indias, I.; Sánchez-Alcoholado, L.; Pérez-Martínez, P.; Andrés-Lacueva, C.; Cardona, F.; Tinahones, F.; Queipo-Ortuño, M.I. Red Wine Polyphenols Modulate Fecal Microbiota and Reduce Markers of the Metabolic Syndrome in Obese Patients. Food Funct. 2016, 7, 1775-1787. [CrossRef] [PubMed]

32. Dodt, M.; Roehr, J.T.; Ahmed, R.; Dieterich, C. FLEXBAR-Flexible Barcode and Adapter Processing for Next-Generation Sequencing Platforms. Biology 2012, 1, 895-905. [CrossRef] [PubMed]

33. Dobin, A.; Davis, C.A.; Schlesinger, F.; Drenkow, J.; Zaleski, C.; Jha, S.; Batut, P.; Chaisson, M.; Gingeras, T.R. STAR: Ultrafast Universal RNA-Seq Aligner. Bioinformatics 2013, 29, 15-21. [CrossRef] [PubMed]

34. Robinson, M.D.; McCarthy, D.J.; Smyth, G.K. Edger: A Bioconductor Package for Differential Expression Analysis of Digital Gene Expression Data. Bioinformatics 2010, 26, 139-140. [CrossRef]

35. Bolyen, E.; Rideout, J.R.; Dillon, M.R.; Bokulich, N.A.; Abnet, C.C.; Al-Ghalith, G.A.; Alexander, H.; Alm, E.J.; Arumugam, M.; Asnicar, F.; et al. Reproducible, Interactive, Scalable and Extensible Microbiome Data Science Using QIIME 2. Nat. Biotechnol. 2019, 37, 852-857. [CrossRef]

36. Caporaso, J.G.; Kuczynski, J.; Stombaugh, J.; Bittinger, K.; Bushman, F.D.; Costello, E.K.; Fierer, N.; Peña, A.G.; Goodrich, J.K.; Gordon, J.I.; et al. QIIME Allows Analysis of High-Throughput Community Sequencing Data. Nat. Methods 2010, 7, 335-336. [CrossRef]

37. Rohart, F.; Gautier, B.; Singh, A.; Lê Cao, K.A. Mixomics: An R Package for ‘Omics Feature Selection and Multiple Data Integration. PLoS Comput. Biol. 2017, 13, e1005752. [CrossRef]

38. Trošt, K.; Ulaszewska, M.M.; Stanstrup, J.; Albanese, D.; De Filippo, C.; Tuohy, K.M.; Natella, F.; Scaccini, C.; Mattivi, F. Host: Microbiome Co-Metabolic Processing of Dietary Polyphenols-An Acute, Single Blinded, Cross-over Study with Different Doses of Apple Polyphenols in Healthy Subjects. Food Res. Int. 2018, 112, 108-128. [CrossRef]

39. Ivey, K.L.; Chan, A.T.; Izard, J.; Cassidy, A.; Rogers, G.B.; Rimm, E.B. Role of Dietary Flavonoid Compounds in Driving Patterns of Microbial Community Assembly. mBio 2019, 10, e01205-19. [CrossRef] [PubMed]

40. Rodríguez-Daza, M.C.; Daoust, L.; Boutkrabt, L.; Pilon, G.; Varin, T.; Dudonné, S.; Levy, E.; Marette, A.; Roy, D.; Desjardins, Y. Wild Blueberry Proanthocyanidins Shape Distinct Gut Microbiota Profile and Influence Glucose Homeostasis and Intestinal Phenotypes in High-Fat High-Sucrose Fed Mice. Sci. Rep. 2020, 10, 2217. [CrossRef] [PubMed]

41. Rodríguez-Morató, J.; Matthan, N.R.; Liu, J.; de la Torre, R.; Chen, C.O. Cranberries Attenuate Animal-Based Diet-Induced Changes in Microbiota Composition and Functionality: A Randomized Crossover Controlled Feeding Trial. J. Nutr. Biochem. 2018, 62, 76-86. [CrossRef] [PubMed]

42. Kemperman, R.A.; Gross, G.; Mondot, S.; Possemiers, S.; Marzorati, M.; Van de Wiele, T.; Doré, J.; Vaughan, E.E. Impact of Polyphenols from Black Tea and Red Wine/Grape Juice on a Gut Model Microbiome. Food Res. Int. 2013, 53, 659-669. [CrossRef]

43. Queipo-Ortuño, M.I.; Boto-Ordóñez, M.; Murri, M.; Gomez-Zumaquero, J.M.; Clemente-Postigo, M.; Estruch, R.; Cardona Diaz, F.; Andrés-Lacueva, C.; Tinahones, F.J. Influence of Red Wine Polyphenols and Ethanol on the Gut Microbiota Ecology and Biochemical Biomarkers. Am. J. Clin. Nutr. 2012, 95, 1323-1334. [CrossRef] [PubMed] 
44. Massot-Cladera, M.; Abril-Gil, M.; Torres, S.; Franch, À.; Castell, M.; Pérez-Cano, F.J. Impact of Cocoa Polyphenol Extracts on the Immune System and Microbiota in Two Strains of Young Rats. Br. J. Nutr. 2014, 112, 1944-1954. [CrossRef] [PubMed]

45. Holscher, H.D. Dietary Fiber and Prebiotics and the Gastrointestinal Microbiota. Gut Microbes 2017, 8, 172-184. [CrossRef]

46. Yang, J.; Martínez, I.; Walter, J.; Keshavarzian, A.; Rose, D.J. In Vitro Characterization of the Impact of Selected Dietary Fibers on Fecal Microbiota Composition and Short Chain Fatty Acid Production. Anaerobe 2013, 23, 74-81. [CrossRef]

47. Mano, F.; Ikeda, K.; Joo, E.; Fujita, Y.; Yamane, S.; Harada, N.; Inagaki, N. The Effect of White Rice and White Bread as Staple Foods on Gut Microbiota and Host Metabolism. Nutrients 2018, 10, 1323. [CrossRef] [PubMed]

48. Oliphant, K.; Allen-Vercoe, E. Macronutrient Metabolism by the Human Gut Microbiome: Major Fermentation by-Products and Their Impact on Host Health. Microbiome 2019, 7, 91. [CrossRef]

49. Jones, R.B.; Alderete, T.L.; Kim, J.S.; Millstein, J.; Gilliland, F.D.; Goran, M.I. High Intake of Dietary Fructose in Overweight/Obese Teenagers Associated with Depletion of Eubacterium and Streptococcus in Gut Microbiome. Gut Microbes 2019, 10, 712-719. [CrossRef]

50. Hervert-Hernández, D.; Pintado, C.; Rotger, R.; Goñi, I. Stimulatory Role of Grape Pomace Polyphenols on Lactobacillus Acidophilus Growth. Int. J. Food Microbiol. 2009, 136, 119-122. [CrossRef]

51. Volstatova, T.; Marsik, P.; Rada, V.; Geigerova, M.; Havlik, J. Effect of Apple Extracts and Selective Polyphenols on the Adhesion of Potential Probiotic Strains of Lactobacillus Gasseri R and Lactobacillus Casei Fmp. J. Funct. Foods 2017, 35, 391-397. [CrossRef]

52. Boesmans, L.; Valles-Colomer, M.; Wang, J.; Eeckhaut, V.; Falony, G.; Ducatelle, R.; Van Immerseel, F.; Raes, J.; Verbeke, K. Butyrate Producers as Potential Next-Generation Probiotics: Safety Assessment of the Administration of Butyricicoccus Pullicaecorum to Healthy Volunteers. mSystems 2018, 3, e00094-18. [CrossRef]

53. Eeckhaut, V.; Machiels, K.; Perrier, C.; Romero, C.; Maes, S.; Flahou, B.; Steppe, M.; Haesebrouck, F.; Sas, B.; Ducatelle, R.; et al. Butyricicoccus Pullicaecorum in Inflammatory Bowel Disease. Gut 2013, 62, 1745-1752. [CrossRef] [PubMed]

54. Wang, Y.; Wang, C.; Huang, J.; Xie, M.; Li, X.; Fu, L. Butyricicoccus Plays a Key Role in Mediating the Antagonism between Probiotic and Antibiotic on Food Allergy. Food Agric. Immunol. 2019, 30, 446-461. [CrossRef]

55. Louis, P.; Flint, H.J. Diversity, Metabolism and Microbial Ecology of Butyrate-Producing Bacteria from the Human Large Intestine. FEMS Microbiol. Lett. 2009, 294, 1-8. [CrossRef] [PubMed]

56. Rivière, A.; Selak, M.; Lantin, D.; Leroy, F.; De Vuyst, L. Bifidobacteria and Butyrate-Producing Colon Bacteria: Importance and Strategies for Their Stimulation in the Human Gut. Front. Microbiol. 2016, 7. [CrossRef] [PubMed]

57. Hiippala, K.; Kainulainen, V.; Kalliomäki, M.; Arkkila, P.; Satokari, R. Mucosal Prevalence and Interactions with the Epithelium Indicate Commensalism of Sutterella spp. Front. Microbiol. 2016, 7. [CrossRef] [PubMed]

58. Wang, L.; Christophersen, C.T.; Sorich, M.J.; Gerber, J.P.; Angley, M.T.; Conlon, M.A. Increased Abundance of Sutterella Spp. And Ruminococcus Torques in Feces of Children with Autism Spectrum Disorder. Mol. Autism 2013, 4, 42. [CrossRef] [PubMed]

59. Díaz-Rúa, R.; Keijer, J.; Caimari, A.; van Schothorst, E.M.; Palou, A.; Oliver, P. Peripheral Blood Mononuclear Cells as a Source to Detect Markers of Homeostatic Alterations Caused by the Intake of Diets with an Unbalanced Macronutrient Composition. J. Nutr. Biochem. 2015, 26, 398-407. [CrossRef] [PubMed]

60. Lear, R.; O'Leary, M.; O’Brien Andersen, L.; Holt, C.C.; Stensvold, C.R.; van der Giezen, M.; Bowtell, J.L. Tart Cherry Concentrate Does Not Alter the Gut Microbiome, Glycaemic Control or Systemic Inflammation in a Middle-Aged Population. Nutrients 2019, 11, 1063. [CrossRef]

61. Kojadinovic, M.; Glibetic, M.; Vucic, V.; Popovic, M.; Vidovic, N.; Debeljak-Martacic, J.; Arsic, A. Short-Term Consumption of Pomegranate Juice Alleviates Some Metabolic Disturbances in Overweight Patients with Dyslipidemia. J. Med. Food 2021. [CrossRef] [PubMed]

62. Most, J.; Penders, J.; Lucchesi, M.; Goossens, G.H.; Blaak, E.E. Gut Microbiota Composition in Relation to the Metabolic Response to 12-Week Combined Polyphenol Supplementation in Overweight Men and Women. Eur. J. Clin. Nutr. 2017, 71, 1040-1045. [CrossRef] [PubMed]

63. Patocka, J.; Bhardwaj, K.; Klimova, B.; Nepovimova, E.; Wu, Q.; Landi, M.; Kuca, K.; Valis, M.; Wu, W. Malus Domestica: A Review on Nutritional Features, Chemical Composition, Traditional and Medicinal Value. Plants 2020, 9, 1408. [CrossRef] [PubMed]

64. Koutsos, A.; Lima, M.; Conterno, L.; Gasperotti, M.; Bianchi, M.; Fava, F.; Vrhovsek, U.; Lovegrove, J.A.; Tuohy, K.M. Effects of Commercial Apple Varieties on Human Gut Microbiota Composition and Metabolic Output Using an in Vitro Colonic Model. Nutrients 2017, 9, 533. [CrossRef]

65. Kleiveland, C.R. Peripheral Blood Mononuclear Cells. In The Impact of Food Bioactives on Health: In Vitro and Ex Vivo Models; Verhoeckx, K., Cotter, P., López-Expósito, I., Kleiveland, C., Lea, T., Mackie, A., Requena, T., Swiatecka, D., Wichers, H., Eds.; Springer International Publishing: Cham, Switzerland, 2015; pp. 161-167. 